\title{
Market Value of Residential Property Using the Value Methodology: A Combined Approach
}

\author{
István Hajnal 1* \\ ${ }^{1}$ Department of Construction Technology and Management, Faculty of Architecture, Budapest University of Technology and \\ Economics, H-1521 Budapest, P. O. B. 91, Hungary \\ * Corresponding author, e-mail: drhajnali@gmail.com
}

Received: 12 July 2019, Accepted: 15 January 2020, Published online: 28 May 2020

\begin{abstract}
Real Estate Valuation and Value Methodology are two consultancy businesses that are similar in name. Both fields have a several decadelong long history, are subject to strict regulations and standards and have their practitioners integrated into prestigious professional organizations. That said, it is very difficult to identify any professional relationship between the two consultancy businesses, given the little overlap between the approaches used. To date, property consultants are yet to use the versatile toolkit of VM.

This article presents a model that combines the hedonic analysis of Real Estate Valuation with the function analysis methods elaborated within VM. Previously resting on a strictly empirical basis, the hedonic model can thus incorporate a value driver vector constructed against end-user criteria, resulting in a more accurate methodology for the establishment of value. The approach described in this article can also be used for a more detailed analysis of other types of property. This article is is an extended version of a conference paper presented at Creative Construction Conference 2019 (Hajnal, 2019).
\end{abstract}

Keywords

Real Estate Valuation, Value Methodology, FAST diagram

\section{Introduction}

Representatives of two consultancy businesses, which are very similar in name, met in a masterclass. The two businesses in question are Real Estate Valuation and Value Methodology. Both fields have a several decade-long long history, are subject to strict regulations and standards and have their practitioners integrated into prestigious professional organizations. That said, it is very difficult to identify any professional relationship between the two consultancy businesses, given the little overlap between the approaches used. While VM uses the opinions and results of property consultants as input data, a survey of the literature appears to suggest that to date, property consultants have not utilized the versatile toolkit of VM.

In the age of Big Data, a series of new methodologies have been added to the tools used to establish the market value of residential property. These new methods based on large samples are collectively referred to as non-traditional methods. Of these non-traditional methods, the hedonic valuation model is used the most frequently in international practice. Rather than seeking to analyze the total value of residential property, research tends to focus on the value added by specific value drivers. The approach and tools comprising VM can be readily used to establish the value of residential property and of property in general. The model presented in this article is the first attempt at using VM's function analysis method to support hedonic valuation.

This paper is subsequently structured as follows: Section 2 describes the basics of Value Methodology and its applications in the construction industry; Section 3 discusses the theoretical foundations of hedonic valuation; Section 4 explains the residential property function model developed on the basis of the preceding sections; finally, conclusions and further recommendations are offered in Section 5.

\section{About Value Methodology}

The story of VM began after World War II, at U.S. corporation General Electric. The first publication on the subject was authored by GE project manager Lawrence D. Miles (1949), followed by his seminal book (Miles, 2015), which has had many editions. Miles laid the foundations of Value Methodology. The methodology is based on the premise 
that designers face severe limitations in improving products if they use the current state of the product as a reference point. VM takes the approach that designers should first explore the fields in which the product is used, and identify specific user needs. They should then specify the functions of the product, i.e. what the product is to be used for in order to satisfy certain needs. Solutions to implement those functions should only be explored subsequently. Using this common approach to development enables costs savings in the region of 10 to $25 \%$. In the U.S., the method was found to be so beneficial that its use has been made mandatory in the arms industry since 1964, in environmental protection since 1978, and as a general obligation in public procurement since 1996 (Fodor, 2011). Value Methodology simultaneously provides a design approach, a systemic development tool, and a decision-planning procedure. Rather than simply looking for the cheaper or better solution, it aims to satisfy the needs (benefits) at the lowest cost (sacrifice). A solution meeting this dual requirement is the means to create a product or service that will be appropriate for the buyer, consumer, or user, i.e. creating a sense of satisfaction in the buyer.

In Value Methodology, value is defined as a ratio of function to resources. VM is a complex decision-planning procedure where the consumer's need is used as a starting point and, with a view to achieving the optimum in technical and economic terms, the relationship between the functions and costs of a product is analyzed and shaped in a closely monitored process using teamwork and constructive criticism in order to obtain a more favourable value (SAVE, 2019). VM is commonly used in a variety of industries, including the construction industry.

VM is used for a wide range of purposes in the construction industry (Ellis et al., 2005). Although construction projects are very well suited for planning, "hard thinking" will not necessarily work because the various stakeholders may have different goals (Arab, 2011; Green, 1994). The use of Value Methodology in the construction industry tends to be problematic due to limitations in either the user's knowledge of VM itself or in the user's experience as a facilitator in the field of VM. Another reason is that in contrast to manufacturing, products in the construction industry are much more complex and involve a far greater number of probability elements and variables (Spaulding et al., 2005). The decision-making systems used in VM must be aligned with the specificities of the construction industry (Luo et al., 2011). In certain countries and areas, VM is difficult to apply due to specific circumstances. In Hong Kong, the obstacles are high land prices, which cannot be influenced by VM, and the friendly tendering procedure (Fong and Shen, 2000), in South Africa, ineffective application is attributed to the lack of communication by a study (Aigbavboa et al., 2016), while in Nigeria participants in the construction industry market are resistant to adopting the new method (Olawumi et al., 2016). Elsewhere, Value Methodology is used in compliance with a formal obligation, yet fails to generate any meaningful benefits due to low expert input (Jaapar et al., 2012; Whyte and Cammarano, 2012). At the same time, in countries where the use of VM is not mandatory, market participants are calling for government measures whereby the use of the methodology would become a required element of the local construction process (Aghimien et al., 2018; Ncube and Rwelamila, 2017; Surlan et al., 2016).

Overall, the literature reports favourable experiences in connection with the application of Value Methodology in the construction industry. Various studies have found that VM can generate savings of 5 to $10 \%$, while also significantly increasing user satisfaction (de Andrade Ruiz et al., 2011; Perera et al., 2011). It is important to introduce $\mathrm{VM}$ in the earliest possible phase of the project, as the benefits to be derived from its application are the greatest in the early phases (SAVE, 2019). Researchers see the way forward in the automation of VM, because when combined with artificial intelligence, the methodology is highly instrumental throughout the implementation process (SAVE, 2019; Shehab and Mahani, 2016).

The use of VM in the field of property is not discussed in the literature. As it stands, the RICS Guidance offering a summary of the VM concept for practicing property experts (RICS, 2017) is the only guide of its nature.

The key component of Value Methodology is function analysis, whereby the product or service concerned is divided into functions that make sense to the user. Miles (2015) describes a function using an active verb and a measurable noun (SAVE, 2019). A common form of function analysis is known as FAST (Function Analysis System Technique) analysis, which was developed by Bytheway in 1965 (Bytheway, 2007). As part of that analysis, the main functions for the user are specified and various subordinate functions are ordered into a function chain according to "how" and "why" they are provided. FAST analysis identifies the complete required functionality of a product, as well as the critical interrelations between its functions.

As far as the author is aware, the links between Real Estate Valuation and VM have not been previously explored in the literature. The Value Methodology for Property Professionals masterclass intended to fill this gap. 
The masterclass was given at the Budapest University of Technology and Economics between 14-17 February 2019. During the course, participants were given an overview of Value Methodology and its application in the construction industry and were introduced to the main VM techniques in the form of a minor task. Participants explored the techniques together and were guided through the entire VM process by means of a case study. In teams, participants explored the possible applications of VM in the areas of property expertise and formulated proposals on the applications in a Brainstorming Section, which they also ranked in the assessment phase. The experts considered the individual VM methods to be readily applicable and supported them in general. In particular, participants supported the application of the FAST diagram in the process of determining Market Value through hedonic valuation (Hajnal, 2019).

\section{Using the hedonic method to establish Market Value}

The hedonic model was first extended to the explanation of property value in 1970 by Kain and Quigley, who used factor analysis to assign 39 variables to 5 classes, then examined regressions and constructed a hedonic formula for the calculation of residential property prices in respect of those classes (Kain and Quigley, 1970).

The underlying principle of the hedonic method is the use of statistical means to estimate the relationship between the price and features of a product. The essence of the model is that the value of a property is broken down into value drivers with a factor assigned to each driver which acts as a "shadow price" and expresses the weight of the given value driver within the total value. The usual linear relationship may be expressed in Eq. (1):

$$
P=\propto+\sum\left(\beta_{i} * x_{i}\right)+\varepsilon
$$

where

$P$ : value of the property,

$\alpha$ : constant,

$\beta_{i}$ : shadow price of value driver $i$,

$x_{i}$ : value driver $i$,

$\varepsilon$ : standard error.

Asymmetric price developments are frequently eliminated through the semi-logarithmic or logarithmic transformation of the variables by using Eq. (2) (Malpezzi, 2008):

$\ln P=\propto+\sum\left(\beta_{i} * \ln x_{i}\right)+\varepsilon$

The advantage of the hedonic methodology is that the marginal effect of each value driver can also be read directly from the results, which facilitates the alignment of property valuation with the professional experiences gained from practice.

At the same time, the hedonic model has the problem that researchers construct value drivers based on empirical considerations. Additionally, the vector of value drivers is determined by the facts and known variables of available databases. These value drivers and their shadow prices are not sufficient to cover all components in the consumer value chain; consequently, only specific, selected value drivers of interest are measured in commonly used hedonic analyses. However, introducing function analysis enables the generation of a full set of consumer functions. This function set covers the complete range of value drivers in the hedonic model.

\section{Function analysis of housing from a market perspective}

The concept outlined above will be illustrated through the example of residential property, a product in the property market that is well known to everyone. Using the logic of VM's FAST diagram, the function analysis was developed for a residential property product from the perspective of the average market participant. The purpose was to describe a set of functions whose value drivers are considered by the consumer in determining the Market Value as a general measure of value. For its user (buyer), a residential property product is supposed to provide housing, while it should also be viable as an investment.

The FAST model of residential property is represented as a rooted tree graph with a formulated root, according to the rule that requires a noun and an active verb, as follows: "The main function of residential property is to satisfy the owner's needs". The following functions branch out from that trunk:

- Provide housing (home); and

- Provide an investment opportunity.

The tree graph continues to branch further out as long as the details at each level can still be described by means of data. The leaves of the rooted tree graph represent user needs corresponding to the value drivers in the hedonic model. Depending on the data available and the analyst's needs, the value drivers can be further broken down or aggregated in a single leaf each. The example model is shown in Fig. 1. In individual branches of the tree, from root to leaf the How-Why logic is followed, where a function of 


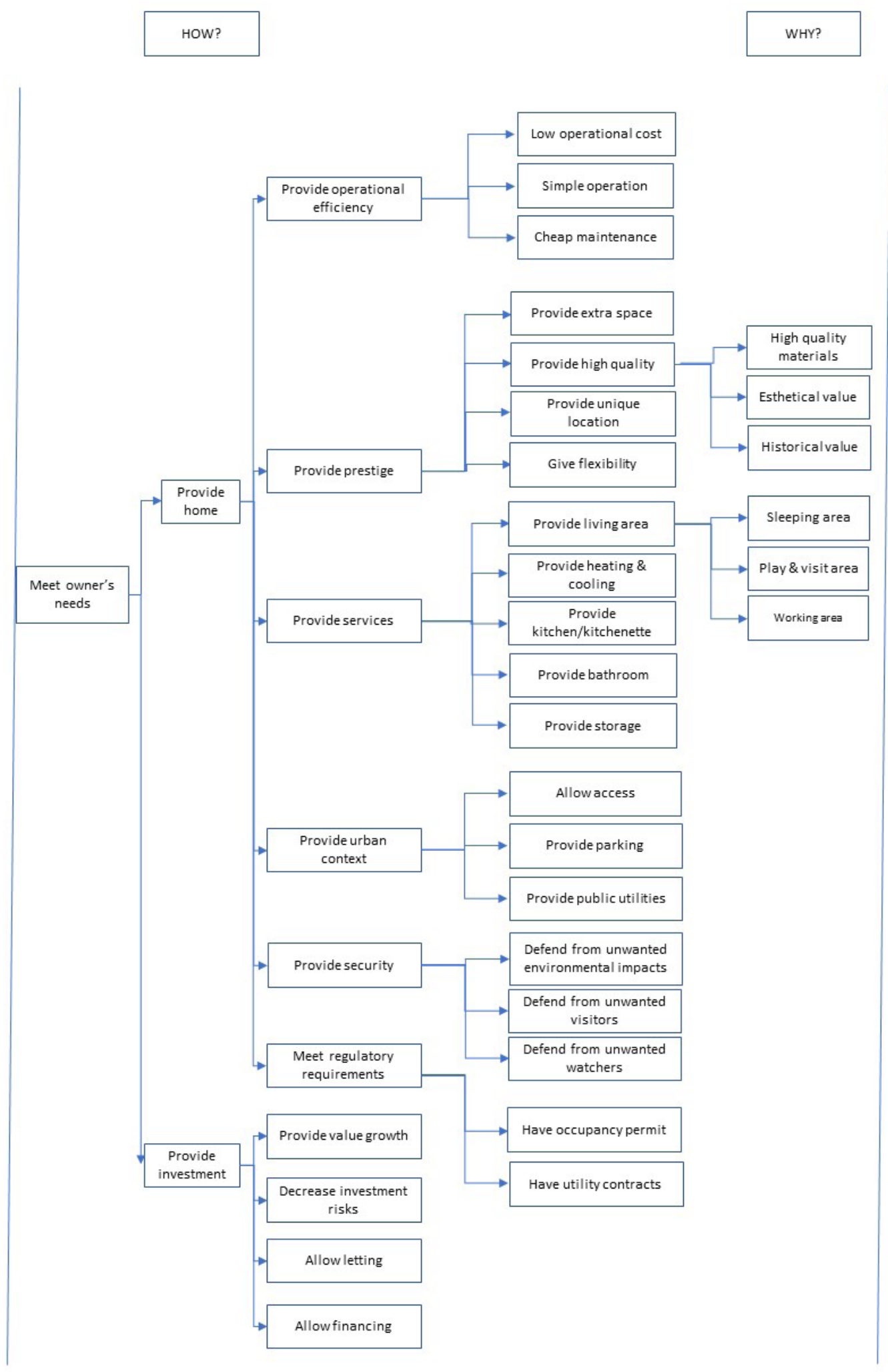

Fig. 1 FAST diagram example 
a higher order is followed by subordinate functions based on the How question. For example, the answers to the question "How does it provide operational efficiency?" are offered by the functions "Low operational cost", "Simple operation", and "Cheap maintenance". In the opposite direction, the answer to the question "Why are operational costs low?", the answer is "Because [the residential property concerned] provides operational efficiency".

The model of the FAST diagram contributes to the establishment of the hedonic Market Value by collectively handling the set of user requirements (which vary in level of detail), allowing the consistent and complete analysis of the records of existing databases. As a result of the systematic structure of the FAST diagram, value drivers are independent of one another. Through the application of the hedonic model, the shadow price $\left(\beta_{i}\right)$ is specified for each leaf of the tree graph.

\section{Conclusion}

The case study on residential property presented in this article confirms that VM is suitable for the development of non-traditional property valuation methods. Further progress requires the following tasks to be carried out:

- Fine-tuning the FAST model presented for residential property;

\section{References}

Aghimien, D., Oke, A. E., Aigbavboa, C. (2018) "Achieving Sustainability in Construction through Value Management", In: Proceedings of the International Conference on Industrial Engineering and Operations Management, Paris, France, 2018, pp. 2442-2448.

Aigbavboa, C., Oke, A., Mojele, S. (2016) "Contribution of value management to construction projects in South Africa", presented at: 5th Construction Management Conference, Cape Town, South Africa, Nov., 28, 2016.

Arab, M. Z. M. (2011) "A Function-Based Cost Model for Early Cost Advice on New-Build Schools Projects", PhD dissertation, Heriot Watt University.

Bytheway, C. W. (2007) "FAST Creativity \& Innovation: Rapidly Improving Processes, Product Development and Solving Complex Problems", J. Ross Publishing, Plantation, FL, USA.

de Andrade Ruiz, J., Granja, A. D., Picchi, F., de Melo, S. (2011) "An Investigation Into The Systematic Use Of Value Engineering In The Product Development Process", presented at: 19th Annual Conference of the International Group for Lean Construction 2011, IGLC 2011, Lima, Peru, Jan., 01, 2011.

Ellis, R. C. T., Wood, G. D., Keel, D. A. (2005) "Value management practices of leading UK cost consultants", Construction Management and Economics, 23(5), pp. 483-493.

https://doi.org/10.1080/01446190500040711
- Running the model on a database of appropriate granularity;

- Evaluating empirical results to assess the soundness of the model;

- Confirming each shadow price by means of other research and surveys;

- Publishing research results for professional users and a more general audience.

Although the approach described in this article is not linked to a specific property market or location, the FAST model will vary by market segment and location.

The masterclass referred to in this article identified additional possible links between VM and Real Estate Valuation, the further exploration of which may add new methodologies and solutions to the traditional tools of property valuation.

\section{Acknowledgement}

The masterclass referred to in this article was given as part of the Knowledge Management program supported by Grant Thornton. Special thanks are owed to the program's instructor, Lucie Parrot for the original idea of the technique described in the article.

Fodor, Á. (2011) "A munkás, de csodálatos értékelemzés" (The difficult, but wonderful Value Analysis), [pdf] MicroVA Fejlesztő Bt., Budapest, Hungary. Available at: http://www.microva.hu/download/File/01beveze.pdf [Accessed: 12 March 2019] (in Hungarian)

Fong, P. S. W., Shen, Q. (2000) "Is the Hong Kong construction industry ready for value management?", International Journal of Project Management, 18(5), pp. 317-326. https://doi.org/10.1016/S0263-7863(99)00028-9

Green, S. D. (1994) "Beyond value engineering: SMART value management for building projects", International Journal of Project Management, 12(1), pp. 49-56.

https://doi.org/10.1016/0263-7863(94)90009-4

Hajnal, I. (2019) "Value Methodology in Real Estate Practice", In: Skibniewski, M. J., Hajdu, M. (eds.) Proceedings of Creative Construction Conference, Budapest, Hungary, pp. 523-528. https://doi.org/10.3311/CCC2019-072

Jaapar, A., Maznan, N. A., Zawawi, M. (2012) "Implementation of Value Management in Public Projects", Procedia-Social and Behavioral Sciences, 68, pp. 77-86. https://doi.org/10.1016/j.sbspro.2012.12.208

Kain, J. F., Quigley, J. M. (1970) "Measuring the Value of Housing Quality", Journal of the American Statistical Association, 65(330), pp. 532-548.

https://doi.org/10.1080/01621459.1970.10481102 
Luo, X., Shen, G. Q., Fan, S., Xue, X. (2011) "A group decision support system for implementing value management methodology in construction briefing", International Journal of Project Management, 29(8), pp. 1003-1017.

https://doi.org/10.1016/j.ijproman.2010.11.003

Malpezzi, S. (2008) "Hedonic Pricing Models: A Selective and Applied Review", In: O'Sullivan, T., Gibb, K. (eds.) Housing Economics and Public Policy, Blackwell Science, Oxford, UK, pp. 67-89. https://doi.org/10.1002/9780470690680.ch5

Miles, L. D. (1949) "How to cut costs with value analysis", McGraw Hill Publishing, New York, NY, USA.

Miles, L. D. (2015) "Techniques of value analysis and engineering", Lawrence D. Miles Value Foundation, Albuquerque, NM, USA.

Ncube, M., \& Rwelamila, P. D. (2017) "Value Management Expertise in the South African Construction Industry-A Case Study of Gauteng", Mega Journal of Business Research, 2017(1), Article number: 27.

Olawumi, T. O., Akinrata, E. B., Arijeloye, B. T. (2016) "Value Management-Creating Functional Value for Construction Project: An Exploratory Study", World Scientific News, 54, pp. 40-59.

Perera, S., Hayles, C. S., Kerlin, S. (2011) "An analysis of value management in practice: the case of Northern Ireland's construction industry", Journal of Financial Management of Property and Construction, 16(2), pp. 94-110 https://doi.org/10.1108/13664381111153097

RICS (2017) "Value Management and Value Engineering", RICS guidance note, Royal Institution of Chartered Surveyors (RICS), London, UK.
SAVE International (2019) "About Value Engineering", [online] Available at: https://www.value-eng.org/page/AboutVE [Accessed: 12 March 2019]

Shehab, T., Mahani, M. (2016) "Hybrid Case-Based Reasoning Approach to Value Engineering in Road Rehabilitation and Traffic Improvement Projects", International Journal of Applied Engineering Research, 11(23), pp. 11199-11206.

Spaulding, W. M., Bridge, A., Skitmore, M. (2005) "The use of function analysis as the basis of value management in the Australian construction industry", Construction Management and Economics, 23(7), pp. 723-731. https://doi.org/10.1080/01446190500040679

Surlan, N., Cekic, Z., Torbica, Z. (2016) "Use of value management workshops and critical success factors in introducing local experience on the international construction projects", Journal of Civil Engineering \& Management, 22(8), pp. 1021-1031. https://oi.org/10.3846/13923730.2014.945950

Whyte, A., Cammarano, C. (2012) "Value management in infrastructure projects in Western Australia: Techniques and staging", In: Smith, S. D. (ed.) Proceedings of the 28th Annual ARCOM Conference, ARCOM, Association of Researchers in Construction Management, Edinburgh, UK, pp. 797-806. 